\title{
The Complexities of Intravenous Fluid Research: Questions of Scale, Volume, and Accumulation
}

\author{
Neil J Glassford, MBChB, MRCP ${ }^{1,2}$, and Rinaldo Bellomo, MBBS, M.D., FRACP, FCICM, FAAHMS ${ }^{1,2,3}$ \\ ${ }^{1}$ Department of Intensive Care, Austin Hospital, Melbourne, ${ }^{2}$ Australian and New Zealand Intensive Care Research Centre, School of Public Health and Preventive Medicine, \\ Monash University, Prahran, ${ }^{3}$ School of Medicine, The University of Melbourne, Parkville, Melbourne, Australia
}

\begin{abstract}
Despite near ubiquity, information regarding fluids consumption at a health care systems level, and patient exposure at an individual level, is surprisingly limited in the medical literature. The epidemiology of the foundational medical intervention of intravenous fluid administration is incredibly complex, with millions of patients being exposed internationally every year. Fluid is being given for different reasons, to different targets, following different triggers, by different specialties in different countries, and any observations that can be made are thought to have limited external validity to other jurisdictions and patient groups. The independent effects of fluid administration and fluid accumulation are very hard to separate from other markers of illness severity and aspects of the process of care. Fluid accumulation can result in organ injury, even when the fluid is being given to purportedly ameliorate or prevent such injury, and if it were independently associated with mortality then would be an easily accessible and modifiable risk factor for subsequent morbidity or death. Despite their ubiquity, it is clear that we have limited understanding of the effects of the intravenous fluids we use daily in the most vulnerable of patient groups. The research agenda in this field is large and urgent.
\end{abstract}

Key Words: fluid bolus therapy; fluid overload; intravenous fluid therapy; mortality; patient-centred outcome; resuscitation.

If you are drowning in water, you will even grasp at a straw. - Proverb

\section{Understanding the scale of intravenous fluid exposure}

Despite near ubiquity, information regarding fluids consumption at a health care systems level and patient exposure at an individual level is surprisingly limited in the medical literature.[1] In general, published studies examine the administration of intravenous fluids to patients in the emergency department, during critical illness, or in the peri-operative period. It is from these studies,[2] and historical estimates of daily water and solute requirements based on physiological reasoning,[3] that clinical guidelines are generated.[4] Outside of these settings, the majority of the fluids literature focuses on prescribing errors by junior medical staff or quality-improvement processes around the provision of intrave-

Received on November 18, 2016 Revised on November 23, 2016 Accepted on November 23, 2016

Correspondence to: Rinaldo Bellomo, Department of Intensive Care, Austin Hospital, 145 Studley Rd, Heidelberg, Melbourne, VIC 3084, Australia

Tel: +61-3-9496 5992, Fax: +61-3-9496 3932

E-mail: Rinaldo.BELLOMO@austin.org.au nous fluids.[5-9] This is not unexpected following several strategic national enquiries into potentially preventable deaths demonstrating significant risks associated with inadequate or excessive intravenous fluid administration. $[10,11]$

*No potential conflict of interest relevant to this article was reported. 


\section{High-level estimation}

At present there are few studies examining the epidemiology of fluid therapy at an intensive care unit (ICU), hospital, health service, or national level in the literature. The only published data on crystalloid solutions that we could identify reported that 10 million litres of $0.9 \%$ saline were sold in the UK in 1999, though the source of this data is uncertain.[12] Given that 8.7 million litres of saline were sold to the public health system over the 2013-14 financial year in Australia and New Zealand,[13] a region with approximately $1 / 3$ of the population of the UK, this figure is likely to be a substantial underestimate. The same source suggested more than 200 million litres of saline are purchased annually in the USA,[12] but a 2013 New York Times article places recent consumption at up to 1 billion units each year.[14] Recent media reports suggested that China may use up to 10 billion units of intravenous fluid, though subsequent government reports stated this figure represents the national production, not consumption, of intravenous fluids.[15] In addition, complex cultural factors suggest significant over-prescription and over-use of parenteral therapies in China. [16] No such information is available for other countries, including South Korea.

Regarding colloid solutions, in a personal communication from an employee of Fresenius Kabi, the world market for colloid consumption in 1994 was estimated at almost 500 million units.[17] In an analysis of reported adverse event using data supplied to the Plasma Protein Therapeutics Association by its constituent member companies, approximately 16 million litre-equivalents of 4\% albumin solution were supplied between 1998 and 2000 internationally.[18] A subsequent investigation examining colloid use in 16 industrialised countries found acquiring data to be very difficult. Only limited data on albumin could be acquired from 15 of the 16 countries, and data regarding synthetic colloid use was only obtainable from 3. In 2004 more than 230,000 litres of synthetic colloids were used in Canada. In Denmark, in 2005, more than 100,000 litres were used and in Sweden more than
170,000 litres were used over the same time period.[19]

Over a five-year period the National Health Service in the UK spent approximately $£ 156$ million per annum on intravenous fluids, which could allow for an estimation of volume.[2] Unfortunately, the British National Formulary does not contain information on the cost of $500 \mathrm{~mL}$ and 1,000 $\mathrm{mL}$ bags of different crystalloid solutions, nor does this information appear to be available from other sources. In our institution, a $1,000 \mathrm{~mL}$ bag of $0.9 \%$ saline costs \$AUD 1.10 and sales of intravenous and dialysis fluids in the state of Victoria are estimated to be worth $\$ 15$ million.[20] However, we were unable to find any centralised estimates of healthcare expenditure for intravenous fluids in the USA or Australia, and extrapolating use from these figures would be complex, both because of regional and sectorial variation in healthcare purchasing and procurement strategies, and the pricing of such therapies.[14,20]

\section{Surrogates of fluid exposure}

In the absence of significant peer-reviewed literature, one method of estimating intravenous global fluid exposure may be by quantifying intravenous cannula use. Five million intravenous cannula devices were used in Australian hospitals in 1994.[21] Assuming a conservative average increase in hospital admission rates of 3\% per annum,[22] it is likely that there are now more than 9 million cannulations, and hence at least this many probable exposures to intravenous fluids, per year in Australia. An apparent 150 to 200 million intravascular devices are purchased each year in the USA and used in approximately 30 million people.[23,24] However, these numbers appear to be projections based on unpublished data[25] and observations more than 35 years old,[26] and so the true current rate of intravenous cannulation in the USA is uncertain. We were unable to identify similar information for UK cannulation rates, and it would seem that extrapolating fluid exposure from cannulation data would be unreliable for many reasons. We could not identify such information for South Korea. 
The use of injection data, estimated from populationbased surveys and injection practice studies, where an injection is any medical procedure piercing the skin or a mucous membrane for the purposes of healthcare, would be similarly unreliable. The last international assessment of injection practice dates to 2000, where age and sex adjusted estimates from the Western Pacific Region B, including South Korea, Cambodia, China, Vietnam and the Philippines, suggest 2.1 to 2.7 exposures per person, per year.[27] These estimates are based on work from China and Taiwan, and their applicability to the rest of the region is unclear. In South East Asian Region B (Indonesia, Sri Lanka, Thailand) 2.1 to 2.2 exposures per person per year were reported, and in South East Asian Region D (including Bangladesh, North Korea, India) 3.8 to 4.2 injections per person per year. These data are much more useful in exploring the overuse and safety of injections, and their association with communicable disease, than in estimating intravenous fluid exposure, with the majority of resultant fluid exposures likely to be small volume vaccination or antibiotic administrations.[27]

It is accepted by the UK National Health Service that there is no extant information on the proportion of patients receiving intravenous fluid therapy, but there are more than 5 million acute hospital admissions per year, and it is likely that the majority are exposed to intravenous fluid therapy.[28] In Australia in 2013-14 there were 9.7 million hospital admissions; $25 \%$ were emergency admissions and 20\% admissions for surgical intervention. Given that a further 1.3 million people were admitted for dialysis that financial year, it is likely that more than 5 million Australians are exposed to intravenous fluids on an annual basis.[22] In 2010, 136.3 million patients attended the emergency department in the USA, with 16.2 million being subsequently admitted and 2.1 million of those being admitted to ICU;[29] there were more than 35 million acute hospital admissions over this time period.[30] From these figures it is likely that between 15 and 30 million exposures to intravenous fluids occur annually in the US, though this is, at best, a rough estimate. This is likely to translate into somewhere between 1 and
3 million patients being exposed to IV fluids in South Korea.

Proprietary information on fluid sales and similar interventions is available, and may be more reliable than these other attempts at quantification.[31] Reports are available at a cost of thousands of dollars to guide companies seeking to invest or venture into the international intravenous fluid market, a market estimated to be worth $\$ 7$ billion dollars by 2017.[32] The use of such data would appear to be an industry standard method of market forecasting. Using such sales data as a surrogate of consumption in combination with national health care statistics may allow the identification of changing trends in fluid preference at a strategic level. However, the accuracy of such data is difficult to identify and may be inherently biased to encourage investment in the market.

It is very hard to develop realistic estimates of national or international consumption of intravenous fluids, but it is obvious that millions of exposures in millions of patients occur in the UK, Australia and the USA alone, and, likely, in South Korea. Understanding the epidemiology of fluid administration at this level in more detail is important. Given the global scale of intravenous fluid exposure even tiny true changes in morbidity or mortality as a consequence of optimising the type, rate or volume of intravenous fluid therapy could potentially have staggering implications for patient-centred outcomes across the world. It could be argued that in the absence of this baseline information, intravenous fluid use almost becomes an "outside context problem," in that it exists, and may be in some way injurious, though this was not anticipated before widespread use.[33] As a result, we have no way to quantify the harm that may ensure, but continue to use intravenous fluids with the ill-defined risks that they may pose, with the assumption that they are safe, because we all use them.

\section{The complexities of early fluid resuscitation} in sepsis

Exploration of the global population risks of intra- 
venous fluid exposure remains limited, and questions of fluid class - crystalloid vs colloid, artificial colloid vs. albumin - or constitution - balanced or unbalanced crystalloid - are complex, and deserve more detailed examination than can be offered here.[34-39] Moreover, in most studies, patients are exposed to a variety of fluids, not just the fluid under investigation, and many exposures - carrier fluids, maintenance fluids or flushes via haemodynamic monitoring pressure systems - are never recorded.

The iconic administration of intravenous fluids in the ICU remains fluid resuscitation, particularly in the setting of sepsis. While aggressive fluid resuscitation remains a cornerstone of early sepsis management in accordance with international guidelines, $[40,41]$ the startling mortality benefits of the single-centre study upon which the modern approach to fluid resuscitation in sepsis have never been duplicated.[42] Though ground breaking, and admirable in its intent, this un-blinded, single-centre trial of early goal directed therapy (EGDT) in 300 patients recruited from the emergency department, with a postintervention mortality rate higher than mortality rates in similar cohorts of septic patients in other jurisdictions at the time, [43-45] has formed the basis of the early bundle of care in sepsis, supported, in the main, by retrospective or observational work.[46]

\section{A bundle of disparate interventions}

Emerging evidence over the last decade has suggested that several key aspects of the EGDT bundle are unlikely to be associated with benefit. For example, the Transfusion Requirements in Septic Shock (TRISS) trial, a multi-centre randomised controlled trial from more than 30 centres across Scandinavia, demonstrated no mortality benefit or differences in organ support or ischaemic events from transfusing red cells at a haemoglobin trigger of $9 \mathrm{~g} / \mathrm{dL}$ compared to $7 \mathrm{~g} / \mathrm{dL}$ in patients with septic shock, with a significant reduction in product usage.[47] The relatively liberal or non-specific transfusion thresholds of EGDT protocols are likely to lead to increased blood exposure for apparent minimal benefit in septic patients.

Targeting fluid resuscitation to a central venous pressure (CVP) of 8-12 $\mathrm{mmHg}$ is part of the initial trial protocol, and subsequent recommendations.[40,42] CVP has been demonstrated to be a poor estimate of blood volume in surgical, or critically ill patients, or those with burns. Moreover, CVP poorly predicts fluid responsiveness to fluid bolus therapy (FBT) in a variety of critically ill populations including cardiac and neurosurgery, sepsis and general ICU patients.[48] In a post-hoc analysis of the 778 patients from the Vasopressin in Septic Shock trial, at $12 \mathrm{~h}$ from inclusion, CVP had a pseudolinear relationship with mortality on Cox regression when adjusted for age and illness severity; thereafter there was no relationship between CVP and outcome.[49] In a French single-centre retrospective observational study of 137 critically ill patients with sepsis, CVP values and fluid balances were significantly greater in patients with acute kidney injury (AKI) than in those without. CVP was independently associated with new or persistent AKI when adjusted for increasing fluid balance and positive end expiratory pressure (odds ratio [OR] for AKI: 1.22 [95\% confidence intervals (CI): $1.08-1.39$ per $1 \mathrm{mmHg}$ increase in CVP]).[50] In a similar Australian study of 107 patients with septic shock, mean perfusion pressure deficit, driven by CVP, was greater in those patients with severe AKI than in those without. When adjusted for sex, illness severity, noradrenaline requirement, fluid balance and mean arterial pressure, CVP remained independently associated with worsening AKI over the first $7 \mathrm{~d}$ of ICU admission (OR for worsening AKI: 1.28 [95\% CI: 1.031.60 per $1 \mathrm{mmHg}$ increase in CVP]).[51] While current guidelines suggest a CVP target as part of the fluid management of severe sepsis, such observations indicate CVP may best serve as a limit for fluid resuscitation.

\section{Harmonising early resuscitative practice -}

Given these concerns, the publication of the Australasian Resuscitation in Sepsis Evaluation (ARISE) 
trial,[52] the Protocolised Management of Sepsis (ProMISe) trial from the UK, [53] and the Protocolized Care for Early Septic Shock (ProCESS) trial from the United States, three modern randomised controlled trials designed to examine the role of EGDT in sepsis,[54] was both timely and useful (Table 1). None of the trials found a survival advantage in the use of EGDT over standard therapy, but EGDT did require more patients to be admitted to ICU, and greater use of blood product, and vasoactive medication. The reported mortality rates in all three trials were substantially lower than in the original study (Table 1). A recent systematic review synthesised the three trials, along with the original EGDT study, and one other admitting patients from the emergency department (ED), in a total of 4735 patients. No difference was found in mortality between those treated with EGDT compared to usual therapy (pooled OR 1.01 [95\% CI: 0.86-1.15], $\mathrm{p}=0.93,\left[\mathrm{I}^{2}\right.$ $=0 \% ; p=0.97])$, or on $90 \mathrm{~d}$ mortality when only the three recent trials were considered alone (pooled OR 0.99 [95\% CI: 0.88-1.16], $\left.\mathrm{p}=0.9,\left[\mathrm{I}^{2}=57 \% ; \mathrm{P}=0.055\right]\right) .[55]$

The importance of early fluid resuscitation in shocked states was highlighted in the Fluid Expansion as Supportive Therapy (FEAST) trial.[56] A methodologically sound, twostrata, multi-centre, open, randomised controlled study, set in Sub-Saharan Africa, this compared the effects of albumin or saline resuscitation with maintenance therapy only on mortality in more than 3,000 children with clinical evidence of impaired perfusion. Children without severe hypotension were randomised to receive $20 \mathrm{~mL} / \mathrm{kg} 5 \%$ albumin, or $0.9 \%$ saline FBT or no FBT at all. None of the resources of modern developed critical care practice were available, and no

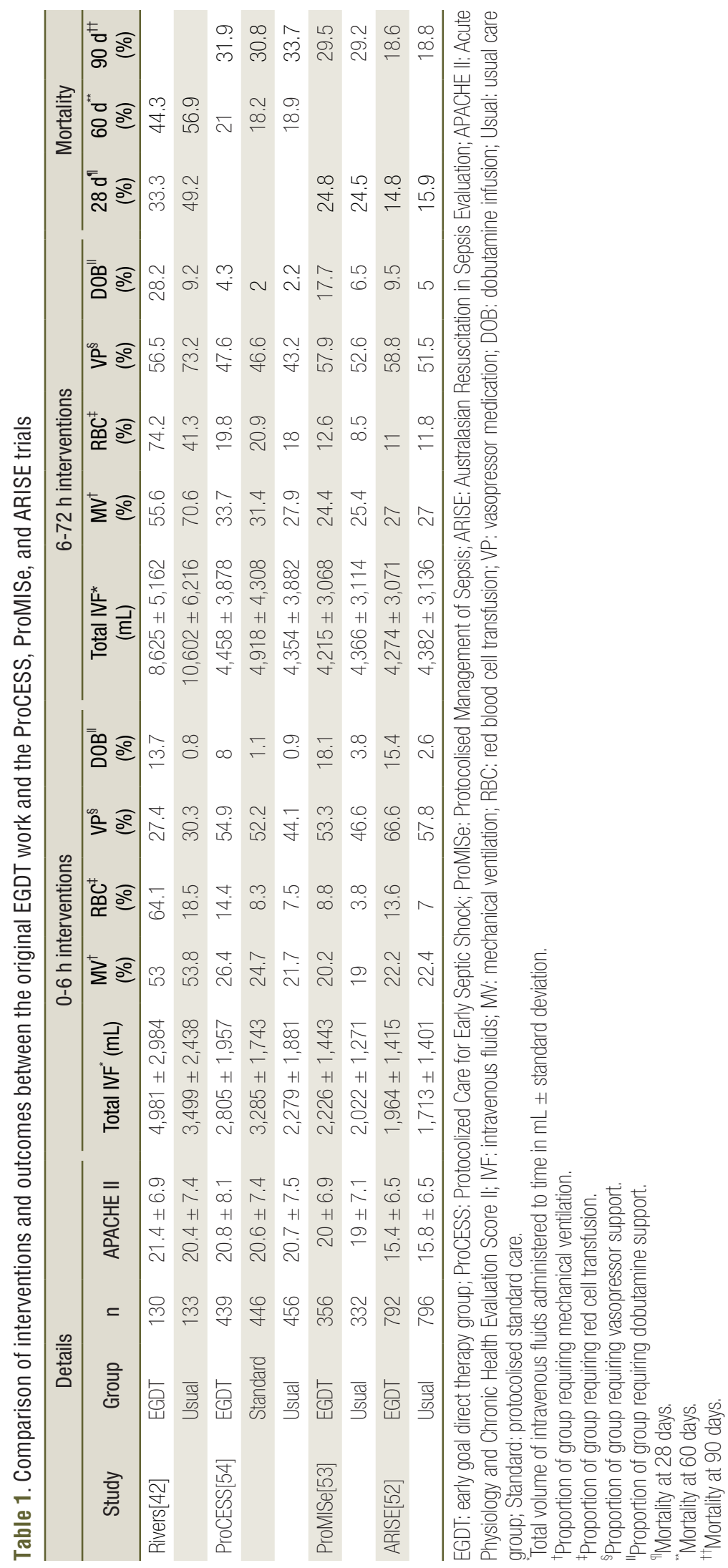


children received invasive ventilation, renal replacement therapy or vasoactive medications due to the resource poor setting of the study. In this austere environment, in children with suspected severe infection, FBT with albumin or saline increased the absolute risk of death by $3.3 \%$ (relative risk: $1.45,95 \% \mathrm{CI} 1.13$ to $1.86 ; \mathrm{p}=0.003$ ), and this mortality difference persisted across all sensitivity and sub-group analyses.[56-58] Most deaths occurred within $48 \mathrm{~h}$ of randomisation, and they occurred after early improvements in indices of perfusion in children receiving FBT. The temporal relationship between FBT administration and improvement are in keeping with recent studies examining the effects of FBT in adults, which suggest a maximal effect immediately following FBT, followed by rapid dissipation over a 10-minute period.[59] Even in the three recent harmonised EGDT trials there are still differences in the volume of fluid given over the first $6 \mathrm{~h}$ and first $72 \mathrm{~h}$ implying differing patterns and trajectories of fluid administration (Table 1). Given the differences in illness severity, use of vasoactive medications, mechanical ventilation and steroids, it is possible that any early harmful effects of rapid early fluid resuscitation could be masked by other critical care interventions.

\section{Liberal and restrictive resuscitation}

On balance, further post-hoc analyses of the evolution of fluid volume variables with time, and the trajectories of early fluid accumulation from these studies, while they may be interesting, would be unlikely to offer as much novel information, or be as directly relevant to patientcentred outcomes, as trials of usual early sepsis care with randomisation to liberal or restrictive fluid regimens. While not directly comparable, the differing utilisation of vasoactive medications, mechanical ventilation, fluid resuscitation and blood transfusion, even between the usual care arms of the ARISE, ProCESS, and ProMISe studies suggests a degree of variation in usual care exists between and within jurisdictions, and that equipoise to allow randomisation may be present. CVP limits, rather than targets, and guidance for early initiation of vasopressor medications in the setting of vasoplegia may offer an acceptable alternative approach to usual care to limit fluid administration.

Of course, harmonisation with previous studies may prove difficult moving forward, given the recent revision of the sepsis concept.[60] However, with the publication of a pilot assessment for the Conservative vs. Liberal Approach to fluid therapy of Septic Shock in Intensive Care (CLASSIC) trial, we can see that such attempts are both feasible and already underway. In 9 ICUs in Finland and Denmark, 151 patients were randomised to restrictive fluid therapy (isotonic crystalloid fluid boluses of 250-500 $\mathrm{mL}$ for evidence of severe hypoperfusion only) or standard care (isotonic crystalloid fluid boluses for as long as haemodynamic improvement observed).

Patients admitted to the ICU within $24 \mathrm{~h}$ of fulfilling sepsis criteria with severe circulatory impairment (SBP < $90 \mathrm{mmHg}$, heart rate $>140 \mathrm{bpm}$, lactate $\geq 4 \mathrm{mmol} / \mathrm{L}$, or use of vasopressors), after an arbitrarily defined as adequate $30 \mathrm{~mL} / \mathrm{kg}$ ideal body weight of fluid in the last $6 \mathrm{~h}$, and requiring on-going noradrenaline support targeting a mean arterial pressure (MAP) of $65 \mathrm{mmHg}$. The hazard ratio (HR) criteria probably lead to a substantial proportion of the final cohort having new or rate-uncontrolled atrial fibrillation (AF). On recent estimates, up to $40-50 \%$ of patients with sepsis, severe sepsis or septic shock may develop AF.[61,62] While accounting for ICU discharge with competing risks survival analysis, a study of over 2,000 patients demonstrated and independent association between AF and ICU mortality following adjustment for age, gender, body mass index, comorbidities, illness severity and sepsis severity at admission. AF both decreased the daily probability of ICU discharge, and increased the daily probability of death.[62] Unfortunately the relationship between AF and fluid balance remains unexplored in patients with sepsis, and in the larger critically ill population, but, given these findings may be an important consideration moving forward with studies with such definitions of septic shock.

The groups were unbalanced, with a suggestion that weight, source of sepsis, incidence of AKI and the vol- 
ume of fluids given in the $24 \mathrm{~h}$ prior to randomisation may have differed. Significant differences were demonstrated between groups in volume of resuscitation fluid given at both Day 5 (restrictive: $500 \mathrm{~mL}$ [0 to 2,500] vs. standard: $2,000 \mathrm{~mL}[1,000$ to 4,100$])$ and over the ICU stay (restrictive: $500 \mathrm{~mL}$ [0 to 3,250$]$ vs. standard: 2,200 $\mathrm{mL}[1,000$ to 4,750$])$, and in cumulative fluid balance at Day 5 (restrictive: $1,752 \mathrm{~mL}[-1,153$ to 3,758$]$ vs. standard: $2,680 \mathrm{~mL}$ [407 to 5,114$]$ ). However, no differences were demonstrated in total fluid input or cumulative fluid balance over the ICU admission. Of note, the volumes of fluid administered by the end of $24 \mathrm{~h}$ when accounting for ED resuscitation, were substantially larger than those used in the recent trials of EGDT.[52-54] No differences were demonstrated between groups in $90 \mathrm{~d}$ mortality or ischaemic event, but AKI was more likely to worsen in patients receiving standard care (restrictive: $37 \%$ vs. standard: $54 \%, \mathrm{p}=0.03$ ).

So, regarding fluid status, the CLASSIC trial demonstrates that restrictive approaches to fluid resuscitation are possible in the ICU, but also highlights the importance of documenting and accounting for resuscitation fluid administered prior to ICU admission, and the difficulties in achieving separation between groups regarding overall fluid administration and fluid balance. This implies that, in the absence of fluid bolus therapy availability, clinicians will offer maintenance or enteral regimens to account for perceived or real deficits.

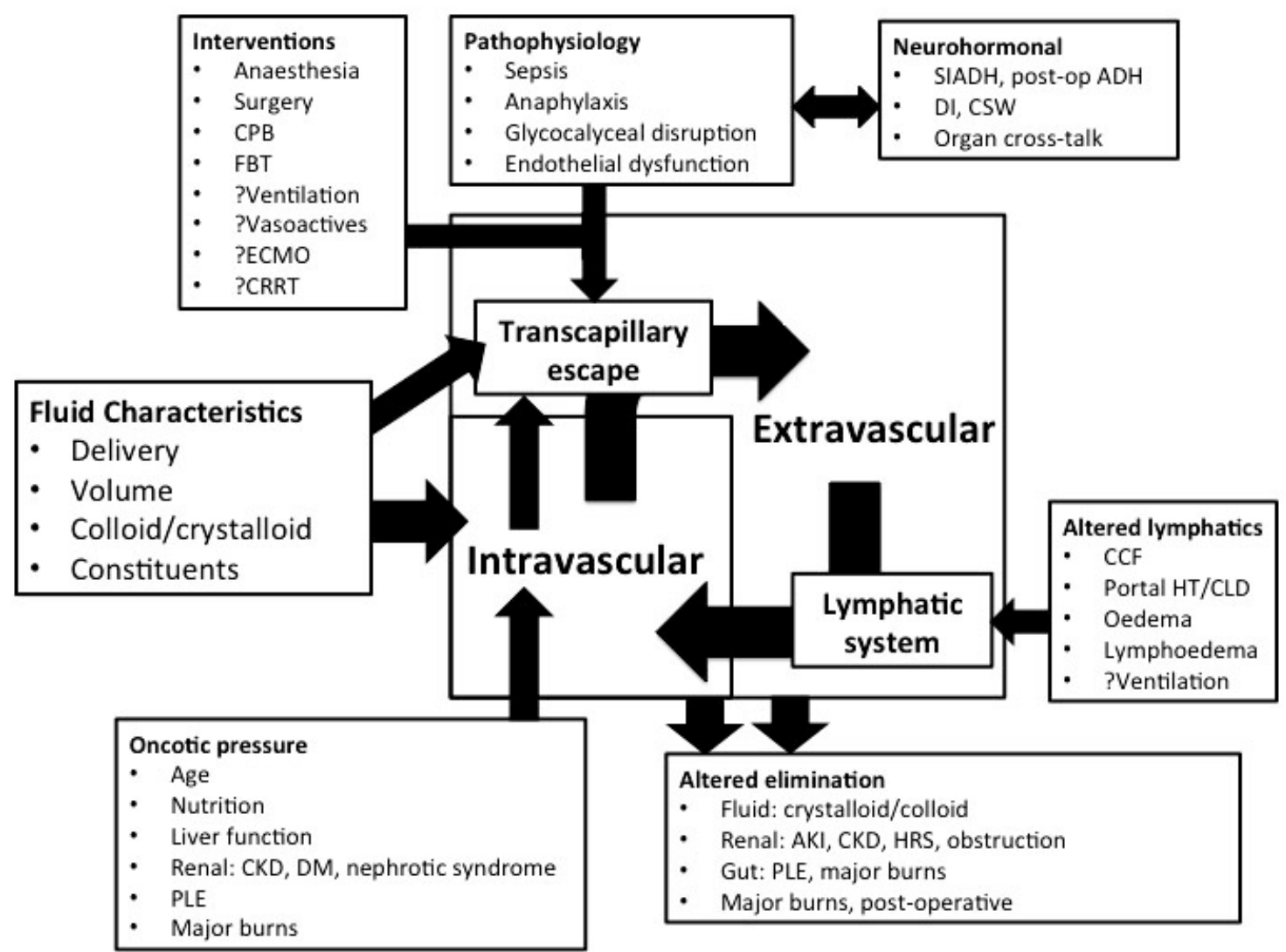

Fig. 1. Mechanisms of fluid accumulation and loss. CPB: cardiopulmonary bypass; FBT: fluid bolus therapy ECMO: extracorporeal membrane oxygenation; CRRT: continuous renal replacement therapy; SIADH: syndrome of inappropriate anti-diuretic hormone secretion; ADH: anti-diuretic hormone; DI: diabetes insipidus; CSW: cerebral salt wasting; CCF: congestive cardiac failure; Portal HT: portal hypertension; CLD: chronic liver disease; AKI: acute kidney injury; CKD: chronic kidney disease; HRS: hepato-renal syndrome; PLE: proteinlosing enteropathy; DM: diabetes mellitus. 


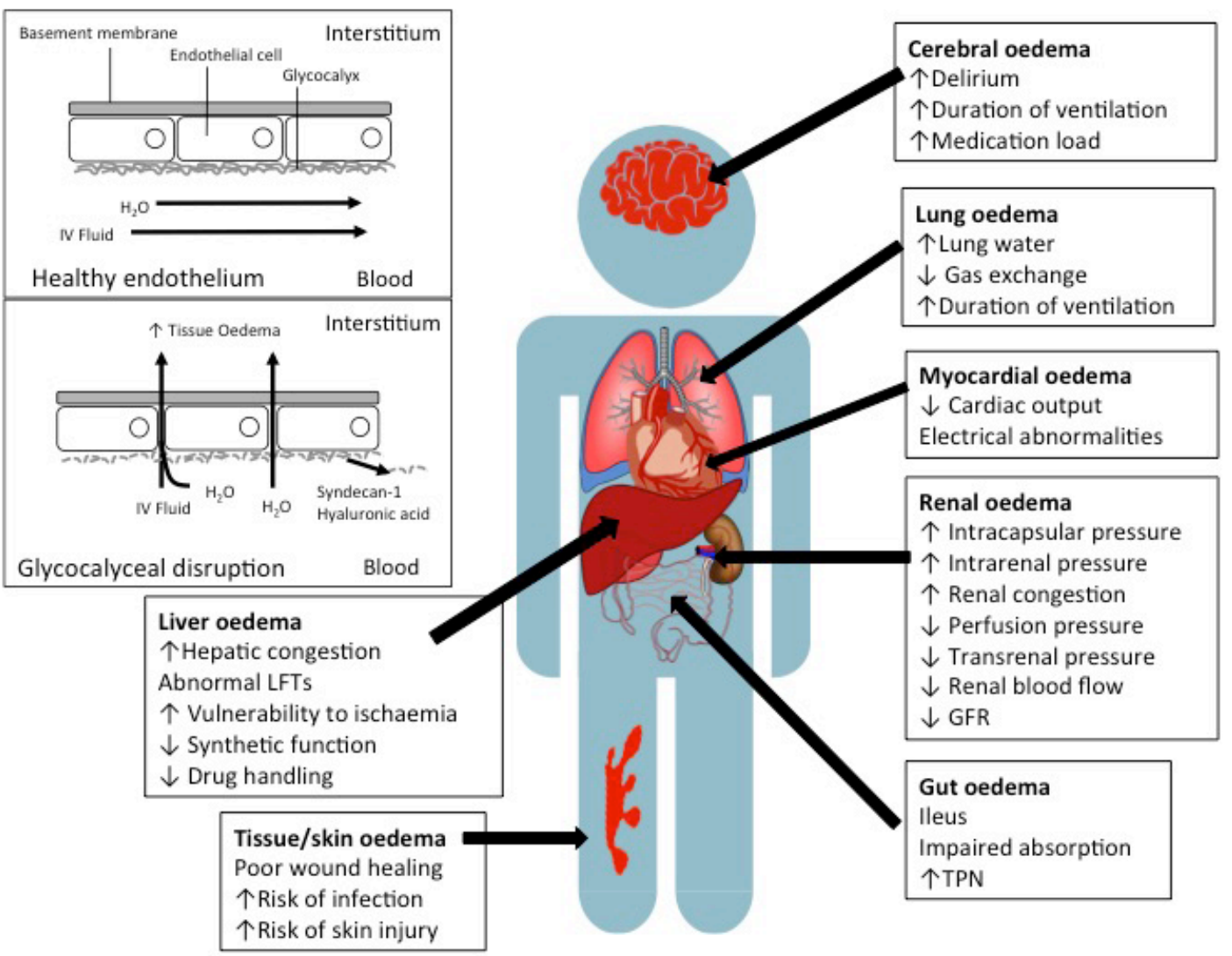

Fig. 2. Consequences of fluid accumulation and oedema at an organ level. LFTs: liver function tests; TPN: total parenteral nutrition.

\section{Adding insult to injury}

Concern regarding tissue oedema and fluid overload has existed since the earliest days of fluid therapy, when it was still being delivered by "proctoclysis" (colonic administration).[63] Though not inevitable, the volume of fluid administered to critically ill patients as part of resuscitation, as a vehicle for drug administration, or in an attempt to optimised haemodynamics often leads to fluid accumulation, and the genesis of a positive fluid balance. [64] This is exacerbated by the presence of comorbidities, such as chronic cardiac, liver, or kidney disease, acute interventions or pathological processes leading to admission, or the development of sequelae of those processes, such as acute kidney injury or multiple organ failure, which prevent elimination (Fig. 1). Fluid administration may lead to venous congestion at an organ level, through a combination of capillary leak and increased central venous pressures. The endothelial glycocalyx plays a vital role in modulating transvascular fluid exchange, and fluid administration has been associated with glycocalyceal damage.[65-67] Glycocalyceal breakdown accelerates transvascular albumin and fluid loss into interstitial tissues, leading to organ oedema and possible dysfunction (Fig. 2).[68] Restoration or protection of the glycocalyx may therefore provide a novel therapeutic target,[68] with syndecan-1 and hyaluronic acid offering promise as potential biomarkers of glycocalyceal disruption. $[65,66]$ Clearance of tissue and organ oedema relies on fluid shifting back into the intravascular space via the lymphatic system, the integrity and function of which remains poorly described during critical illness (Fig. 1). $[68,69]$

The association between elevations in CVP and renal outcome discussed above are probably the most easily observable consequence of tissue oedema. As an encap- 


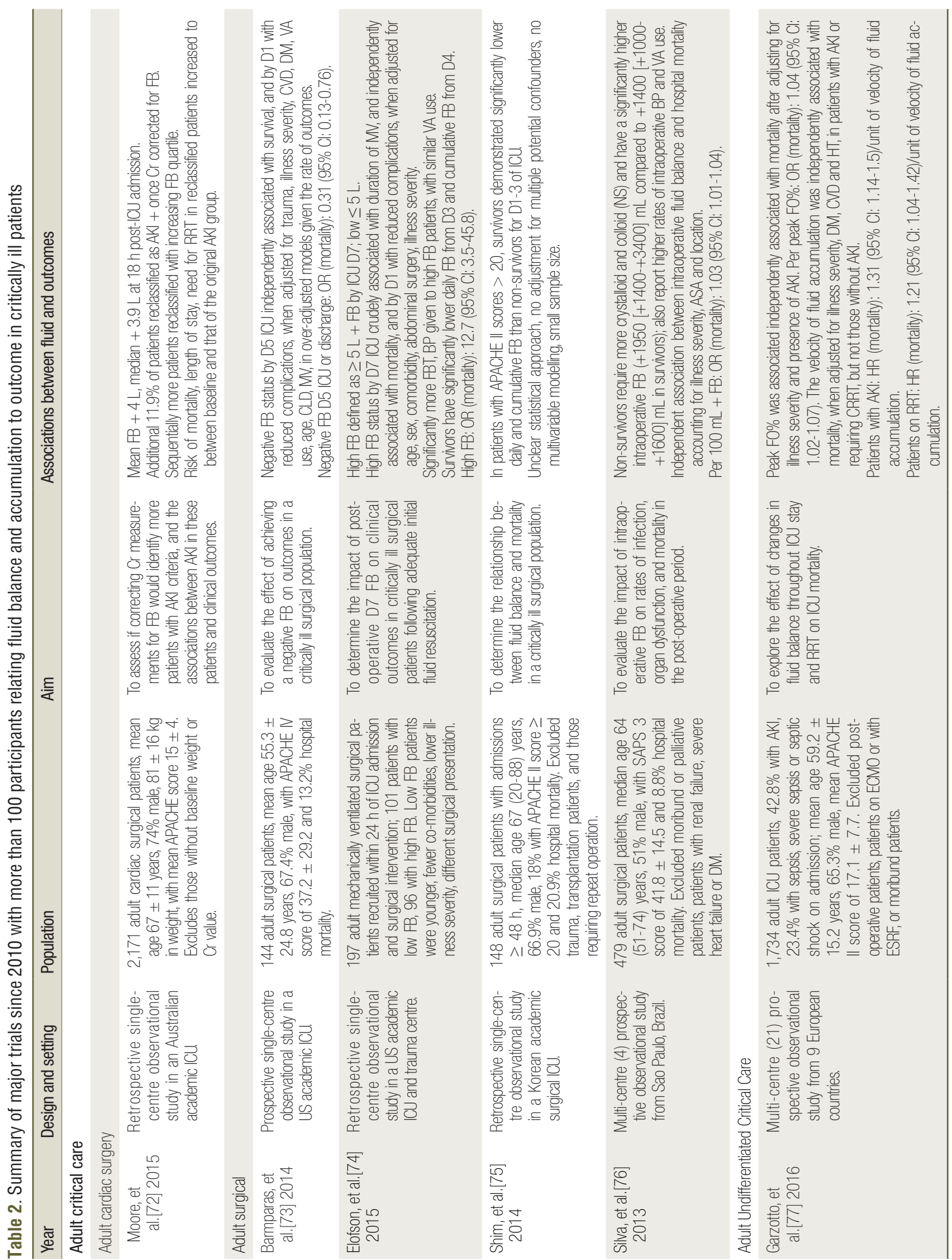




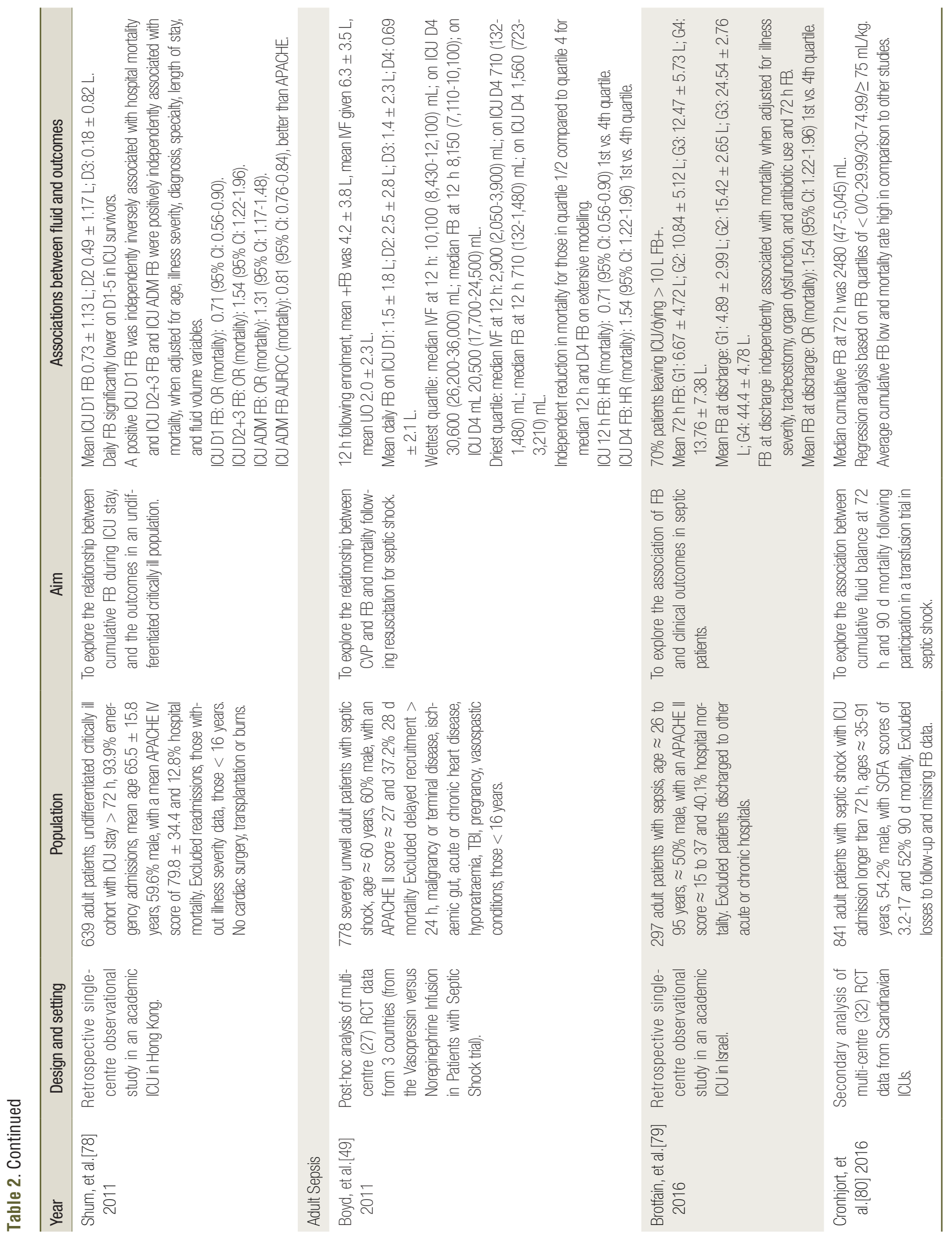




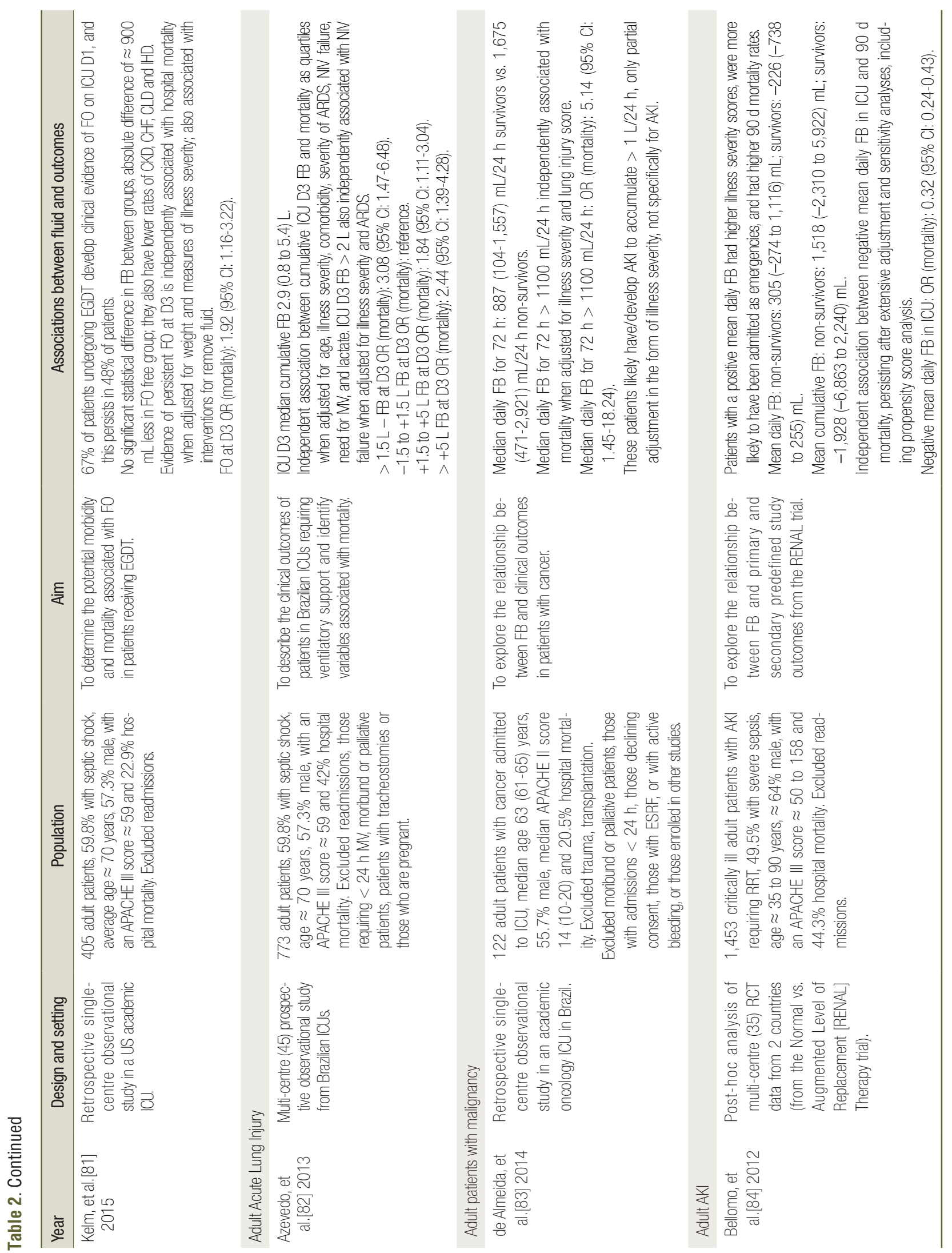




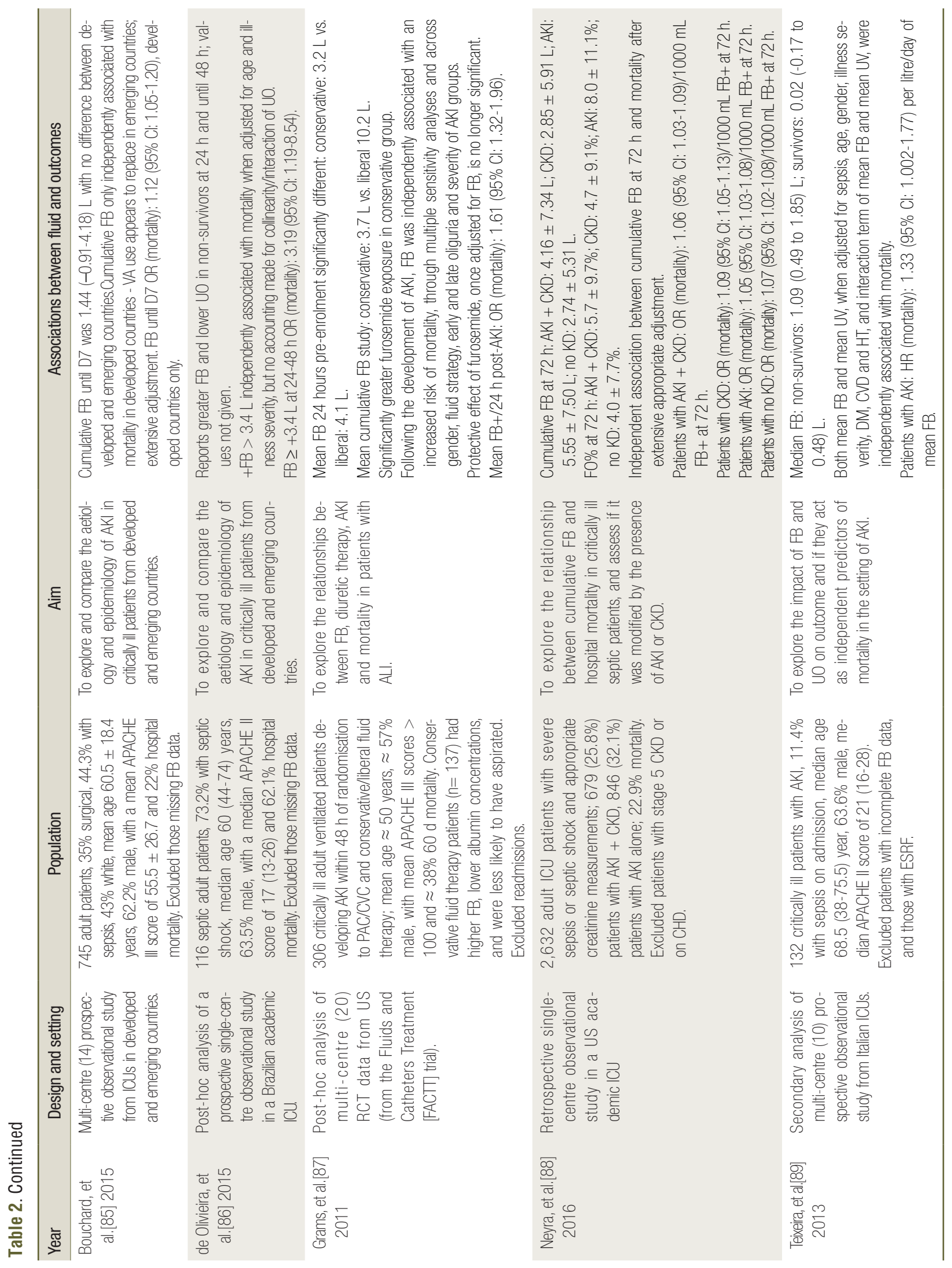




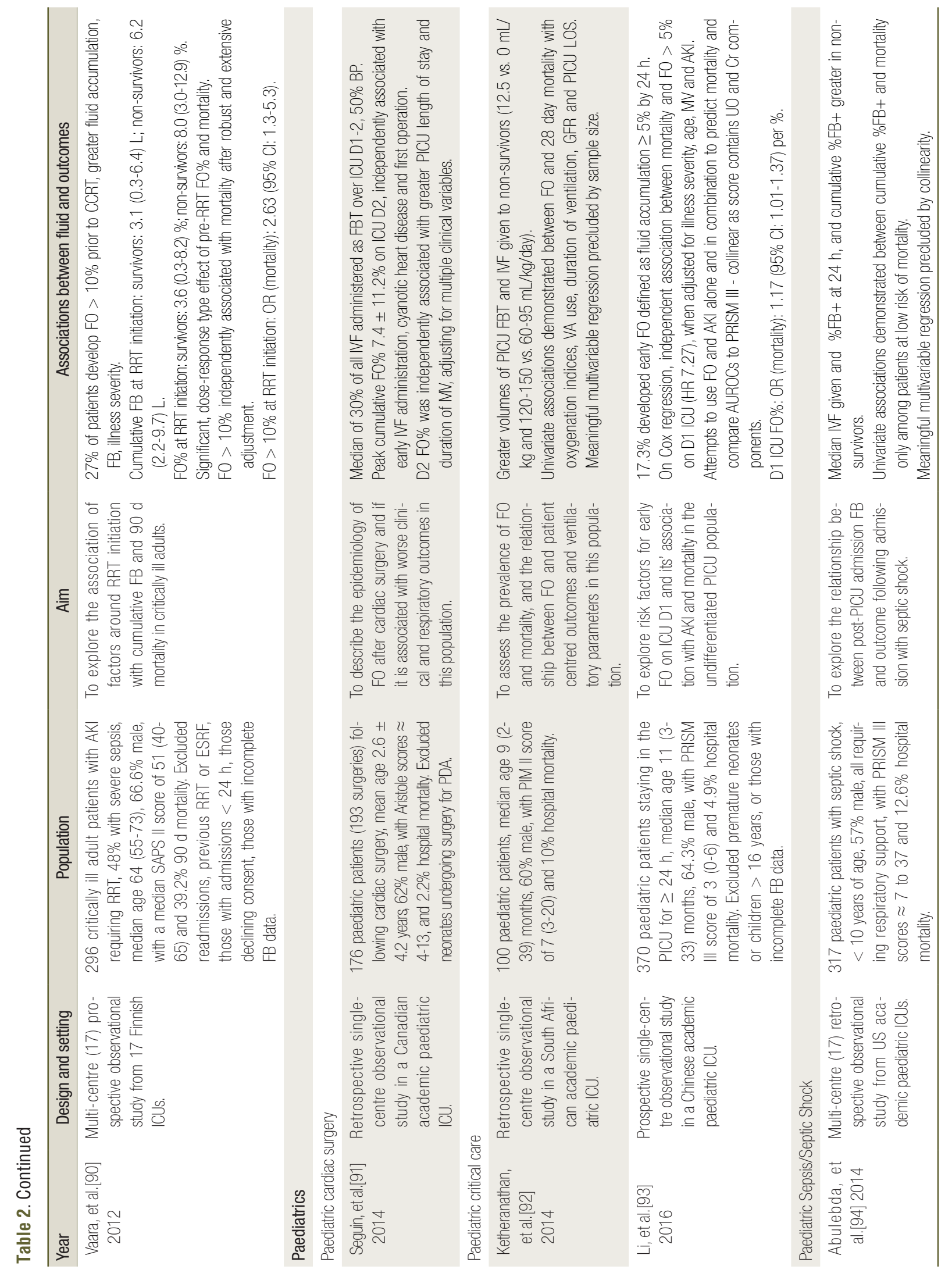




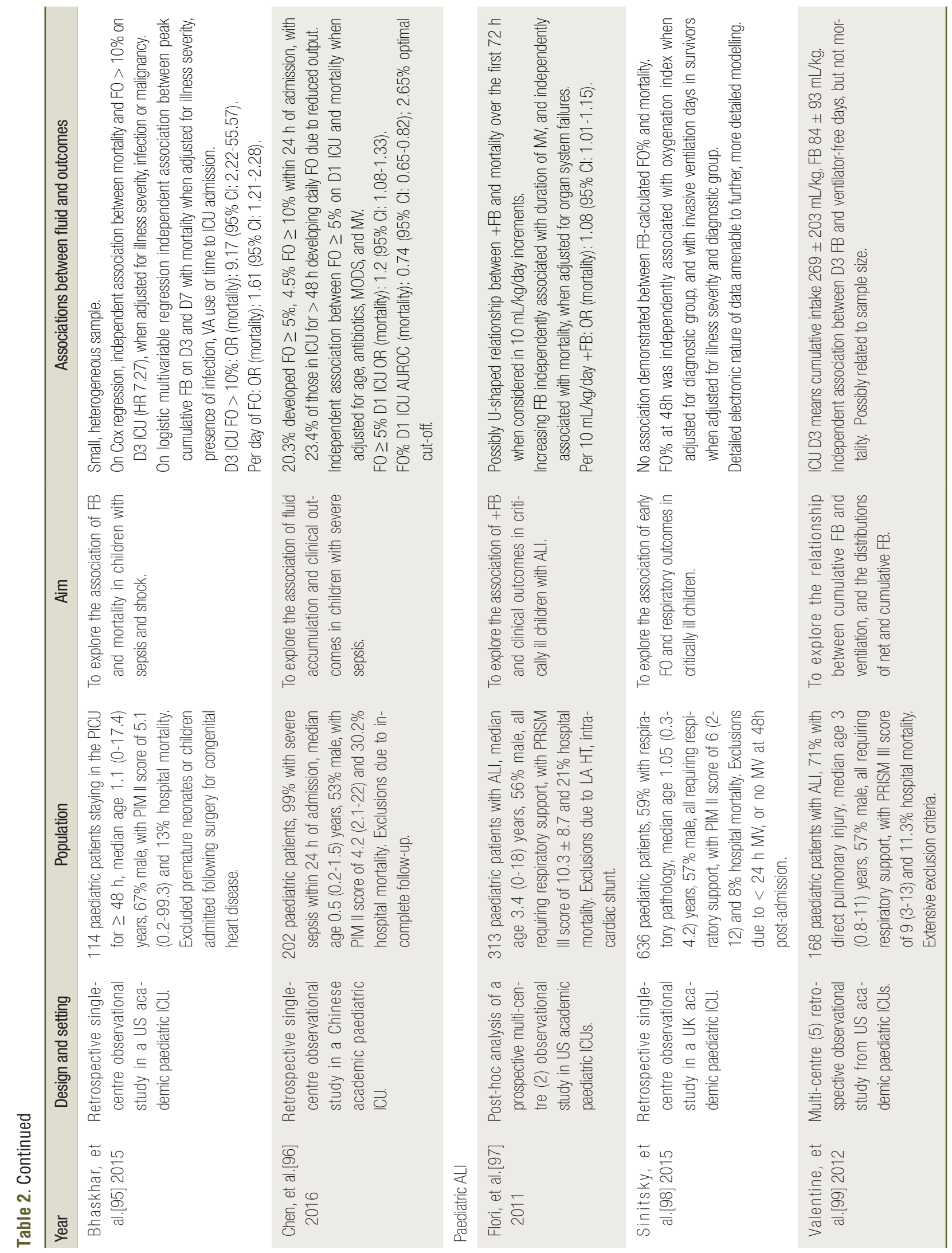




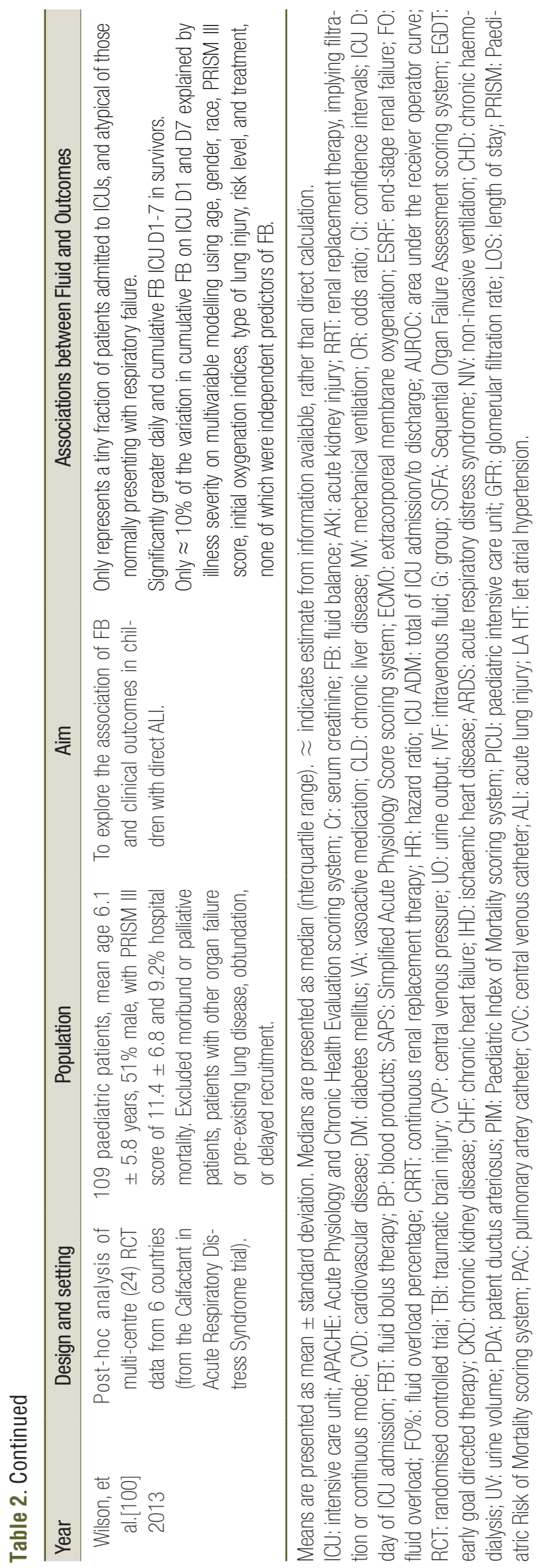

sulated organ, increases in the renal volume will lead to rapid increases in intrarenal pressure and this, in turn, may reduce the trans-organ perfusion pressure gradient and hence organ blood flow.[48-51] The overall effect of these processes may contribute to an increased vulnerability of the organ to subsequent insults, and concomitant organ failure (Fig. 2). It is unclear if this relationship is unidirectional, but backpressure from the renal circulation may then contribute centrally to elevated right heart pressure through myocardial oedema, diastolic dysfunction and right heart dysfunction.

The clinical effects of fluid accumulation have been well documented, classically in the Vasopressin versus Norepinephrine Infusion in Patients with Septic Shock[49] and Fluids and Catheters Treatment[70] trials, and by the Program to Improve Care in Acute Renal Disease group,[71] and more recently in a variety of patient cohorts. Independent associations between fluid accumulation in the ICU and mortality have been demonstrated in adult patients post-cardiac surgery,[72] postoperatively,[73-76] in general critical illness,[77,78] with sepsis/septic shock,[49,79-81] with acute lung injury,[82] with malignancy,[83] and with AKI,[84-90] and in children post-cardiac surgery,[91] with general critical illness,[92,93] with sepsis/septic shock,[94-96] and with acute lung injury.[97-100] Table 2 presents select studies, published since 2010 and where $\mathrm{n}>100$, demonstrating persistent and pervasive associations between fluid balance, overload or accumulation and mortality in these patient groups, across a variety of circumstances, approaches and regions (Table 2).

\section{Evidence from Korea}

Observational work offers some insights into local practice.[101] The association between changes in body weight and clinical outcomes were explored in a prospective observational study of 140 adult patients, $77 \%$ male, with a mean age of 66 years and a mean Acute Physiology and Chronic Health Evaluation Score (APACHE) II score of 20.6, admitted to the ICU of a Ko- 
rean University hospital. The majority, 95.7\%, were ventilated, $43.6 \%$ had severe sepsis on admission, and ICU mortality was $23.6 \%$. Non-survivors were more likely to have presented with sepsis or acute respiratory distress syndrome (ARDS), and have underlying cerebrovascular disease. They had greater increases in weight (ICU D2: 0.9 vs. $0.3 \mathrm{~kg}$ ) and fluid balance (ICU D2: 1.43 vs. $0.6 \mathrm{~L}$ ) than survivors from ICU D2 to D7.[101] Bland-Altman analysis suggested a systematic bias and limits of agreement too wide to be clinically useful, in keeping with previous work.[102] Though a significant correlation was demonstrated between fluid balance and weight gain, no interaction variables were introduced, nor was adjustment made for fluid balance on multivariable modelling. Weight gain on ICU Day 3-6 was independently associated with ICU mortality when adjusted for age, illness severity and presence of sepsis or ARDS. However, a stronger association between mortality and fluid balance on Days 2, 3, 4, 6, and 7 was arguably demonstrated on univariate analysis.[101] While not presented, an exploration of the effect of the interaction of weight and fluid balance on mortality may have offered additional value.

The relationship between fluid balance and mortality was retrospectively explored in a single-centre cohort of 148 adult surgical patients admitted for $\geq 48 \mathrm{~h}$, with a median age of 67 years, $66.9 \%$ male, $18 \%$ with an APACHE II score $\geq 20,58 \%$ undergoing emergency surgery, with $20.9 \%$ dying in hospital.[75] The ICU did not receive trauma or post-transplantation patients, and those requiring repeat operation on the same admission were excluded from the analysis. Survivors were younger and had lower illness severity scores, but no difference was noted on crude analysis in fluid balance on ICU Day1-3. When stratified by APACHE II scores $\leq>>20$, daily and cumulative balances on Day1-3 of ICU were demonstrated to be significantly lower in survivors than non-survivors.[75] No adjustment or multivariable modelling was attempted, but given the small sample size the results of such attempts would be of uncertain significance.

In 100 patients undergoing renal replacement therapy the relationship between pre-initiation fluid balance and organ outcome and mortality was explored.[103] Patients with end-stage renal failure or following trauma, or surgery, were excluded. The majority were emergency admissions (65\%), and the cohort had a median age of 65 years, median Sequential Organ Failure Assessment scoring system (SOFA) scores of 9-11, with $67 \%$ being male, and $68 \% 28 \mathrm{~d}$ mortality. Patients were grouped by daily fluid balance prior to renal replacement therapy (RRT) initiation: $37 \%$ had a fluid balance of $<1.5 \mathrm{~L}$, $31 \% 1.5$ to $3 \mathrm{~L}$ and $32 \%>3 \mathrm{~L}$. Patients in the higher fluid balance groups had non-significant increases in the median CVP, use of diuretics and presence of pulmonary oedema at RRT initiation, and significant increases in all components of the SOFA score. Increasing fluid balance was independently associated with all organ systems failure when adjusted for age, sex and the degree of system dysfunction on ICU admission, and with mortality when adjusted for age, sex, illness severity and the cause of AKI requiring continuous renal replacement therapy. [103] Given the small sample size, definitive conclusions are difficult to make, but the findings are consistent with those internationally (Table 2), and it would appear that the strong observational associations between fluid accumulation and adverse outcomes found in the critically ill in other geographical areas are mirrored in the South Korean population.

\section{Systematic assessments of fluid adminis- tration and accumulation}

Even the physiological effects of fluid resuscitation are uncertain. While indices may improve temporarily, a recent systematic review found little evidence of clinically significant changes with a median increase in cardiac index of $800 \mathrm{~mL} / \mathrm{min} / \mathrm{m}^{2}$ (6 studies), median reduction in HR of $2 \mathrm{bpm}$ (8 studies), median increase in MAP of $7 \mathrm{mmHg}$ (8 studies), and median increase in CVP of 3.2 mmHg ( 5 studies) at the very end of an episode of FBT. Thirty minutes later, however, compared to original baseline, an increase in cardiac index of $300 \mathrm{~mL} / \mathrm{min} / \mathrm{m}^{2}$ (3 studies), median reduction in HR of $2 \mathrm{bpm}$ (5 stud- 
ies), median increase in MAP of $7.5 \mathrm{mmHg}$ (5 studies), and median increase in CVP of $3 \mathrm{mmHg}$ (4 studies) were observed.[104] More recent assessments of FBT in the $\mathrm{ED},[105]$ in septic patients in the ICU,[106] and Bayesian assessments of the persistence of the haemodynamic effects of FBT in critically ill patients $[59,107]$ suggest that the immediate benefits of FBT are short-lived, and often of minimal clinical significance. Fluid responsiveness is an extensively studied concept, but a phenomenon that has not to our knowledge been independently associated with an improved clinical outcome, and which has multiple different definitions, each dependent on different interventions, different measurements and different timings of such measurements.[108,109] Moreover, fluid responsiveness is often tautologically and retrospectively defined by participants' responses to the therapy.

In an interesting systematic review of studies attempting to reduce or control cumulative fluid balance in the ICU, almost 20,000 patients were studied across 47 clinically and methodologically profoundly heterogeneous studies and populations. Comparing 8,135 patients treated with restrictive fluid management regimens compared to 7,812 with liberal fluid management regimens, the authors suggest a survival advantage for fluid restriction (OR: 0.42 [95\% CI: 0.32-0.55]). When comparing 2,836 survivors and 2,609 non-survivors at Day 7 of ICU admission, pooled mean difference in cumulative fluid balance favoured survivors $(-4.43 \mathrm{~L}[-5.83$ to -3.04$])$.[110]

Though admirable in its scope, the meta-analytic techniques utilised in this review are methodologically questionable given the mixing of randomised, observational and case-series data. Of particular interest is the authors attempt to begin to ontologically refine the language of fluid balance, administration and accumulation research. [110] However, such definitions should come as the result of robust observational and pilot randomised data.

\section{Moving forward}

While observational data exploring fluid balance and outcomes are plentiful, and include relevant regional studies, there has been little randomised controlled interventional work, and extrapolating the results of Western fluid studies to the ethnically, genetically and culturally distinct populations of South East Asia and the Western Pacific may not be appropriate. Multi-centre, multinational collaborations examining the use of liberal and restrictive fluid regimens in the management of the critically ill would help to reduce our knowledge deficit, and the challenges of international collaboration could be ameliorated by partnering with established critical care research networks such as the Scandinavian or Canadian Critical Care Trials Groups, or the Australian and New Zealand Intensive Care Society Clinical Trials Group.

The CLASSIC trial has demonstrated that studies using restrictive fluid resuscitative practices in the ICU are possible; such approaches need now be extended to the emergency department (ED) to explore the necessity of the currently recommended large volumes of initial resuscitation of up to $30 \mathrm{~mL} / \mathrm{kg}$, for which there is little independent evidence of benefit. Albumin, while demonstrated on subgroup analysis to have a potential mortality benefit in patients with severe sepsis and septic shock, has yet to have this advantage confirmed in an appropriately powered trial.[111,112] Albumin use, given the haemodynamic changes post-administration appear to be equivalent if $100 \mathrm{~mL}$ of $20 \%$ or $500 \mathrm{~mL}$ of $4 \%$ solution are given suggest small volume albumin resuscitation may be a safe mechanism to limit fluid administration. [113] An alternative approach would be early vasoactive use after restricted initial resuscitation. While one study suggests early initiation of vasopressors may be harmful in the primary resuscitation phase, the data was collected over an 18-year period,[114] and an analysis of a larger data set by the same group suggests that marked delays of $>14 \mathrm{~h}$ are associated with increased mortality in patients with septic shock, not early initiation.[115] A smaller contemporary study from China in surgical ICU patients suggests a higher mortality when vasopressors are commenced more than $2 \mathrm{~h}$ from the onset of septic shock.[116] Safe and effective early vasopressor use is very likely to depend on the cohort in which it is used. 
Diuretic medications could form part of restrictive fluid regimens, allowing fluid balance, not fluid administration to be targeted. Comparison between early and delayed renal replacement therapy (with or without initial diuretic therapy) could allow the examination of fluid removal kinetics and the effects of fluid balances. This is a broad topic, and has been explored elsewhere.[64]

\section{Conclusions}

The epidemiology of the foundational medical intervention of intravenous fluid administration is incredibly complex. It is impossible to estimate from current sources how many exposures to intravenous fluids occur internationally on a daily or even yearly basis. However, exposures must number in the millions when maintenance fluids and fluid as a vehicle for drug administration are taken into account alongside fluid used for the purposes of haemodynamic optimisation. Moreover, when fluid is being given for different reasons, to different targets, following different triggers, by different specialties in different countries, any observations that can be made have limited external validity. In most studies, patients are exposed to a variety of fluids, not just the fluid under investigation. The independent effects of fluid administration and fluid accumulation are very hard to separate from other markers of illness severity and aspects of the process of care. Fluid accumulation can result in organ injury, even when the fluid is being given to ameliorate or prevent such injury. Despite their ubiquity, it is clear that we have limited understanding of the effects of the intravenous fluids we use daily in the most vulnerable of patient groups. The research agenda in this field is large and urgent.

\section{Acknowledgements}

The Avant Doctors-In-Training Research Scholarship supports Dr Glassford. This review was supported by an unrestricted educational grant from the Austin Hospital Anaesthesia and Intensive Care Trust Fund.
ORCID

Neil J Glassford ～http://orcid.org/0000-0003-1647-3745

Rinaldo Bellomo http://orcid.org/0000-0002-1650-8939

\section{References}

1) Hilton AK, Bellomo R: A critique of fluid bolus resuscitation in severe sepsis. Crit Care 2012; 16: 302.

2) National Institute for Health and Care Excellence: Intravenous Fluid Therapy in Adults: Clinical Guideline. London, National Institute for Health and Care Excellence. 2013.

3) Holliday MA, Segar WE: The maintenance need for water in parenteral fluid therapy. Pediatrics 1957; 19: 823-32.

4) Leach R: Fluid management on hospital medical wards. Clin Med (Lond) 2010; 10: 611-5.

5) Eastwood GM, Peck L, Young H, Prowle J, Vasudevan $\mathrm{V}$, Jones $\mathrm{D}$, et al: Intravenous fluid administration and monitoring for adult ward patients in a teaching hospital. Nurs Health Sci 2012; 14: 265-71.

6) Ferenczi E, Datta SS, Chopada A: Intravenous fluid administration in elderly patients at a London hospital: a two-part audit encompassing ward-based fluid monitoring and prescribing practice by doctors. Int $\mathbf{J}$ Surg 2007; 5: 408-12.

7) Hilton AK, Pellegrino VA, Scheinkestel CD: Avoiding common problems associated with intravenous fluid therapy. Med J Aust 2008; 189: 509-13.

8) Lim CT, Dunlop M, Lim CS: Intravenous fluid prescribing practices by foundation year one doctors - a questionnaire study. JRSM Short Rep 2012; 3: 64.

9) Rooker JC, Gorard DA: Errors of intravenous fluid infusion rates in medical inpatients. Clin Med (Lond) 2007; 7: 482-5.

10) Callum KG, Gray AJG, Hoile RW, Ingram GS, Martin IC, Sherry KM, et al: Extremes of age. In: National Confidential Enquiry into Perioperative Deaths: London, National Confidential Enquiry into 
Perioperative Deaths. 1999.

11) Findlay GP, Goodwin APL, Protopapa K, Smith NCE, Mason M: A review of the peri-operative care of surgical patients. In: National Confidential Enquiry into Patient Outcome and Death: London, National Confidential Enquiry into Patient Outcome and Death. 2011.

12) Chowdhury AH, Cox EF, Francis ST, Lobo DN: A randomized, controlled, double-blind crossover study on the effects of $2-\mathrm{L}$ infusions of $0.9 \%$ saline and plasma-lyte ${ }^{\circledR} 148$ on renal blood flow velocity and renal cortical tissue perfusion in healthy volunteers. Ann Surg 2012; 256: 18-24.

13) Glassford NJ, French CJ, Bailey M, Mârtensson J, Eastwood GM, Bellomo R: Changes in intravenous fluid use patterns in Australia and New Zealand: evidence of research translating into practice. Crit Care Resusc 2016; 18: 78-88.

14) Bernstein N: The 10,000 Percent Solution [Internet]. New York, New York Times Company; c2013. [cited 2013 Aug 25]. Available from: http://www.nytimes. com/2013/08/27/health/exploring-salines-secretcosts.html.

15) Yuan S: China should reduce the overuse of intravenous infusion. BMJ 2014; 348: g1262.

16) Reynolds L, McKee M: Serve the people or close the sale? Profit-driven overuse of injections and infusions in China's market-based healthcare system. Int J Health Plann Manage 2011; 26: 449-70.

17) Nolan J: Fluid replacement. Br Med Bull 1999; 55: $821-43$

18) Vincent JL, Wilkes MM, Navickis RJ: Safety of human albumin--serious adverse events reported worldwide in 1998-2000. Br J Anaesth 2003; 91: 625-30.

19) Jones D, McEvoy S, Merz TM, Higgins A, Bellomo R, Cooper JD, et al: International albumin use: 1995 to 2006. Anaesth Intensive Care 2010; 38: 266-73.

20) Pearson DDR: Procurement Practices in the Health Sector [Internet]. Melbourne, Victorian Auditor-General's Office, c2011. [cited 2011 Oct]. Available from: http://www.audit.vic.gov.au/publications/20111026-
Health-Procurement/20111026-Health-Procurement. pdf.

21) Collignon PJ: Intravascular catheter associated sepsis: a common problem. The Australian Study on Intravascular Catheter Associated Sepsis. Med J Aust 1994; 161: 374-8.

22) Australian Institute of Health and Welfare: Admitted patient care 2014-14: Australian hospital statistics. Bruce, Australian Institute of Health and Welfare. 2015.

23) Bregenzer T, Conen D, Sakmann P, Widmer AF: Is routine replacement of peripheral intravenous catheters necessary? Arch Intern Med 1998; 158: 151-6.

24) Maki DG: Improving the safety of peripheral intravenous catheters. BMJ 2008; 337: a630.

25) Maki DG: The epidemiology and prevention of nosocomial blood-stream infections [Abstract]. In: Third international conference on nosocomial infections. Atlanta, Georgia. 1990.

26) Maki DG: Nosocomial bacteremia. An epidemiologic overview. Am J Med 1981; 70: 719-32.

27) Hutin YJ, Hauri AM, Armstrong GL: Use of injections in healthcare settings worldwide, 2000: literature review and regional estimates. BMJ 2003; 327: 1075.

28) National Institute for Health and Care Excellence: Intravenous fluid therapy in adults in hospital: costing statement. London, National Institute for Health and Care Excellence. 2013.

29) National Center for Health Statistics. National Ambulatory Medical Care Survey: 2010. Hyattsville, Center for Disease Control. 2011.

30) National Center for Health Statistics. National Hospital Care Survey: 2010. Hyattsville, Center for Disease Control. 2011.

31) QuintilesIMS: IMS Health [Internet] Durham, QuintilesIMS; c2015. [cited 2015 Sep 24]. Available from: http://www.imshealth.com/portal/site/imshealth/ menuitem.051a1939316f851e170417041ad8c22a/?vg nextoid=7311e590cb4dc310 VgnVCM100000a48d2ca 2RCRD\&vgnextchannel=7311e590cb4dc310VgnVC M100000a48d2ca2RCRD\&vgnextfmt=default. 
32) King M: Intravenous (IV) Solutions: A Global Strategic Business Report [Internet]. London, Vertical Edge Limited; c2011. [cited 2015 Jun 15]. Available from: http://www.companiesandmarkets.com/News/ Chemicals/Intravenous-IV-Solutions-A-GlobalStrategic-Business-Report/NI2514.

33) Banks IM: Excession. London, Orbit books. 1996.

34) Myburgh JA: Fluid resuscitation in acute illness-time to reappraise the basics. N Engl J Med 2011; 364: 2543-4.

35) Myburgh JA: Fluid resuscitation in acute medicine: what is the current situation? J Intern Med 2015; 277: 58-68.

36) van Beest PA, Spronk PE, Kuiper MA, Scheeren TW: Colloids and crystalloids: the story continues. Crit Care Med 2014; 42: e676.

37) Young P, Bailey M, Beasley R, Henderson S, Mackle D, McArthur C, et al: Effect of a buffered crystalloid solution vs saline on acute kidney injury among patients in the intensive care unit: the SPLIT randomized clinical trial. JAMA 2015; 314: 1701-10.

38) Yunos NM, Bellomo R, Story D, Kellum J: Benchto-bedside review: chloride in critical illness. Crit Care 2010; 14: 226.

39) Zadrobilek E, Hackl W, Sporn P, Steinbereithner K: Effect of large volume replacement with balanced electrolyte solutions on extravascular lung water in surgical patients with sepsis syndrome. Intensive Care Med 1989; 15: 505-10.

40) Dellinger RP, Levy MM, Rhodes A, Annane D, Gerlach H, Opal SM, et al: Surviving sepsis campaign: international guidelines for management of severe sepsis and septic shock: 2012. Crit Care Med 2013; 41: 580-637.

41) de Oliveira CF, de Oliveira DS, Gottschald AF, Moura JD, Costa GA, Ventura AC, et al: ACCM/PALS haemodynamic support guidelines for paediatric septic shock: an outcomes comparison with and without monitoring central venous oxygen saturation. Intensive Care Med 2008; 34: 1065-75.

42) Rivers E, Nguyen B, Havstad S, Ressler J, Muzzin A,
Knoblich B, et al: Early goal-directed therapy in the treatment of severe sepsis and septic shock. N Engl J Med 2001; 345: 1368-77.

43) Kaukonen KM, Bailey M, Suzuki S, Pilcher D, Bellomo R: Mortality related to severe sepsis and septic shock among critically ill patients in Australia and New Zealand, 2000-2012. JAMA 2014; 311: 1308-16.

44) Martin GS, Mannino DM, Eaton S, Moss M: The epidemiology of sepsis in the United States from 1979 through 2000. N Engl J Med 2003; 348: 1546-54.

45) Angus DC, Linde-Zwirble WT, Lidicker J, Clermont G, Carcillo J, Pinsky MR: Epidemiology of severe sepsis in the United States: analysis of incidence, outcome, and associated costs of care. Crit Care Med 2001; 29: 1303-10.

46) Levy MM, Dellinger RP, Townsend SR, LindeZwirble WT, Marshall JC, Bion J, et al: The surviving sepsis campaign: results of an international guideline-based performance improvement program targeting severe sepsis. Crit Care Med 2010; 38: $367-74$.

47) Holst LB, Haase N, Wetterslev J, Wernerman J, Guttormsen AB, Karlsson S, et al: Lower versus higher hemoglobin threshold for transfusion in septic shock. N Engl J Med 2014; 371: 1381-91.

48) Marik PE, Baram M, Vahid B: Does central venous pressure predict fluid responsiveness? A systematic review of the literature and the tale of seven mares. Chest 2008; 134: 172-8.

49) Boyd JH, Forbes J, Nakada TA, Walley KR, Russell JA: Fluid resuscitation in septic shock: a positive fluid balance and elevated central venous pressure are associated with increased mortality. Crit Care Med 2011; 39: 259-65.

50) Legrand M, Dupuis C, Simon C, Gayat E, Mateo J, Lukaszewicz AC, et al: Association between systemic hemodynamics and septic acute kidney injury in critically ill patients: a retrospective observational study. Crit Care 2013; 17: R278.

51) Wong BT, Chan MJ, Glassford NJ, Mårtensson J, Bion V, Chai SY, et al: Mean arterial pressure and 
mean perfusion pressure deficit in septic acute kidney injury. J Crit Care 2015; 30: 975-81.

52) ARISE Investigators; ANZICS Clinical Trials Group, Peake SL, Delaney A, Bailey M, Bellomo R, et al: Goal-directed resuscitation for patients with early septic shock. N Engl J Med 2014; 371: 1496-506.

53) Mouncey PR, Osborn TM, Power GS, Harrison DA, Sadique MZ, Grieve RD, et al: Trial of early, goaldirected resuscitation for septic shock. N Engl J Med 2015; 372: 1301-11.

54) ProCESS Investigators, Yealy DM, Kellum JA, Huang DT, Barnato AE, Weissfeld LA, et al: A randomized trial of protocol-based care for early septic shock. N Engl J Med 2014; 370: 1683-93.

55) Angus DC, Barnato AE, Bell D, Bellomo R, Chong CR, Coats TJ, et al: A systematic review and metaanalysis of early goal-directed therapy for septic shock: the ARISE, ProCESS and ProMISe Investigators. Intensive Care Med 2015; 41: 1549-60.

56) Maitland K, Kiguli S, Opoka RO, Engoru C, OlupotOlupot P, Akech SO, et al: Mortality after fluid bolus in African children with severe infection. N Engl J Med 2011; 364: 2483-95.

57) Berend K: Mortality after fluid bolus in African children with sepsis. N Engl J Med 2011; 365: 1349; author reply 1351-3.

58) Maitland K, George EC, Evans JA, Kiguli S, OlupotOlupot P, Akech SO, et al: Exploring mechanisms of excess mortality with early fluid resuscitation: insights from the FEAST trial. BMC Med 2013; 11: 68.

59) Aya HD, Ster IC, Fletcher N, Grounds RM, Rhodes A, Cecconi M: Pharmacodynamic analysis of a fluid challenge. Crit Care Med 2016; 44: 880-91.

60) Singer M, Deutschman CS, Seymour CW, ShankarHari M, Annane D, Bauer M, et al: The third international consensus definitions for sepsis and septic shock (Sepsis-3). JAMA 2016; 315: 801-10.

61) Meierhenrich R, Steinhilber E, Eggermann C, Weiss M, Voglic S, Bögelein D, et al: Incidence and prognostic impact of new-onset atrial fibrillation in pa- tients with septic shock: a prospective observational study. Crit Care 2010; 14: R108.

62) Klein Klouwenberg PM, Frencken JF, Kuipers S, Ong DS, Peelen LM, van Vught LA, et al: Incidence, predictors and outcomes of new-onset atrial fibrillation in critically Ill patients with sepsis: a cohort study. Am J Respir Crit Care Med 2016 Jul 28 [Epub]. http://dx.doi.org/10.1164/rcem.201603-06180C.

63) Awad S, Allison SP, Lobo DN: The history of $0.9 \%$ saline. Clin Nutr 2008; 27: 179-88.

64) O'Connor ME, Prowle JR: Fluid overload. Crit Care Clin 2015; 31: 803-21.

65) Berg S, Golster M, Lisander B: Albumin extravasation and tissue washout of hyaluronan after plasma volume expansion with crystalloid or hypooncotic colloid solutions. Acta Anaesthesiol Scand 2002; 46: 166-72.

66) Bruegger D, Schwartz L, Chappell D, Jacob M, Rehm M, Vogeser M, et al: Release of atrial natriuretic peptide precedes shedding of the endothelial glycocalyx equally in patients undergoing on- and off-pump coronary artery bypass surgery. Basic Res Cardiol 2011; 106: 1111-21.

67) Chappell D, Bruegger D, Potzel J, Jacob M, Brettner F, Vogeser M, et al: Hypervolemia increases release of atrial natriuretic peptide and shedding of the endothelial glycocalyx. Crit Care 2014; 18: 538.

68) Woodcock TE, Woodcock TM: Revised starling equation and the glycocalyx model of transvascular fluid exchange: an improved paradigm for prescribing intravenous fluid therapy. Br J Anaesth 2012; 108: 384-94.

69) Jacob M, Chappell D, Becker BF: Regulation of blood flow and volume exchange across the microcirculation. Crit Care 2016; 20: 319.

70) National Heart, Lung, and Blood Institute Acute Respiratory Distress Syndrome (ARDS) Clinical Trials Network, Wiedemann HP, Wheeler AP, Bernard GR, Thompson BT, Hayden D, et al: Comparison of two fluid-management strategies in acute lung injury. $\mathrm{N}$ Engl J Med 2006; 354: 2564-75. 
71) Bouchard J, Soroko SB, Chertow GM, Himmelfarb J, Ikizler TA, Paganini EP, et al: Fluid accumulation, survival and recovery of kidney function in critically ill patients with acute kidney injury. Kidney Int 2009; 76: 422-7.

72) Moore E, Tobin A, Reid D, Santamaria J, Paul E, Bellomo R: The impact of fluid balance on the detection, classification and outcome of acute kidney injury after cardiac surgery. J Cardiothorac Vasc Anesth 2015; 29: 1229-35.

73) Barmparas G, Liou D, Lee D, Fierro N, Bloom M, Ley E, et al: Impact of positive fluid balance on critically ill surgical patients: a prospective observational study. J Crit Care 2014; 29: 936-41.

74) Elofson KA, Eiferman DS, Porter K, Murphy CV: Impact of late fluid balance on clinical outcomes in the critically ill surgical and trauma population. J Crit Care 2015; 30: 1338-43.

75) Shim HJ, Jang JY, Lee SH, Lee JG: The effect of positive balance on the outcomes of critically ill noncardiac postsurgical patients: a retrospective cohort study. J Crit Care 2014; 29: 43-8.

76) Silva JM Jr, de Oliveira AM, Nogueira FA, Vianna PM, Pereira Filho MC, Dias LF, et al: The effect of excess fluid balance on the mortality rate of surgical patients: a multicenter prospective study. Crit Care 2013; 17: R288.

77) Garzotto F, Ostermann M, Martín-Langerwerf D, Sánchez-Sánchez M, Teng J, Robert R, et al: The dose response multicentre investigation on fluid assessment (DoReMIFA) in critically ill patients. Crit Care 2016; 20: 196.

78) Shum HP, Lee FM, Chan KC, Yan WW: Interaction between fluid balance and disease severity on patient outcome in the critically ill. J Crit Care 2011; 26: 613-9.

79) Brotfain E, Koyfman L, Toledano R, Borer A, Fucs $\mathrm{L}$, Galante $\mathrm{O}$, et al: Positive fluid balance as a major predictor of clinical outcome of patients with sepsis/ septic shock after ICU discharge. Am J Emerg Med 2016; 34: 2122-6.
80) Cronhjort M, Hjortrup PB, Holst LB, Joelsson-Alm E, Mårtensson J, Svensen C, et al: Association between fluid balance and mortality in patients with septic shock: a post hoc analysis of the TRISS trial. Acta Anaesthesiol Scand 2016; 60: 925-33.

81) Kelm DJ, Perrin JT, Cartin-Ceba R, Gajic O, Schenck L, Kennedy CC: Fluid overload in patients with severe sepsis and septic shock treated with early goal-directed therapy is associated with increased acute need for fluid-related medical interventions and hospital death. Shock 2015; 43: 68-73.

82) Azevedo LC, Park M, Salluh JI, Rea-Neto A, SouzaDantas VC, Varaschin P, et al: Clinical outcomes of patients requiring ventilatory support in Brazilian intensive care units: a multicenter, prospective, cohort study. Crit Care 2013; 17: R63.

83) de Almeida JP, Palomba H, Galas FR, Fukushima JT, Duarte FA, Nagaoka D, et al: Positive fluid balance is associated with reduced survival in critically ill patients with cancer. Acta Anaesthesiol Scand 2012; 56: 712-7.

84) RENAL Replacement Therapy Study Investigators, Bellomo R, Cass A, Cole L, Finfer S, Gallagher $\mathrm{M}$, et al: An observational study fluid balance and patient outcomes in the Randomized Evaluation of Normal vs. Augmented Level of Replacement Therapy trial. Crit Care Med 2012; 40: 1753-60.

85) Bouchard J, Acharya A, Cerda J, Maccariello ER, Madarasu RC, Tolwani AJ, et al: A prospective international multicenter study of AKI in the intensive care unit. Clin J Am Soc Nephrol 2015; 10: 1324-31.

86) de Oliveira FS, Freitas FG, Ferreira EM, de Castro I, Bafi AT, de Azevedo LC, et al: Positive fluid balance as a prognostic factor for mortality and acute kidney injury in severe sepsis and septic shock. J Crit Care 2015; 30: 97-101.

87) Grams ME, Estrella MM, Coresh J, Brower RG, Liu KD; National Heart, Lung, and Blood Institute Acute Respiratory Distress Syndrome Network: Fluid balance, diuretic use, and mortality in acute kidney injury. Clin J Am Soc Nephrol 2011; 6: 966-73. 
88) Neyra JA, Li X, Canepa-Escaro F, Adams-Huet B, Toto RD, Yee J, et al: Cumulative fluid balance and mortality in septic patients with or without acute kidney injury and chronic kidney disease. Crit Care Med 2016; 44: 1891-900.

89) Teixeira C, Garzotto F, Piccinni P, Brienza N, Iannuzzi M, Gramaticopolo S, et al: Fluid balance and urine volume are independent predictors of mortality in acute kidney injury. Crit Care 2013; 17: R14.

90) Vaara ST, Korhonen AM, Kaukonen KM, Nisula $\mathrm{S}$, Inkinen $\mathrm{O}$, Hoppu $\mathrm{S}$, et al: Fluid overload is associated with an increased risk for 90-day mortality in critically ill patients with renal replacement therapy: data from the prospective FINNAKI study. Crit Care 2012; 16: R197.

91) Seguin J, Albright B, Vertullo L, Lai P, Dancea A, Bernier PL, et al: Extent, risk factors, and outcome of fluid overload after pediatric heart surgery*. Crit Care Med 2014; 42: 2591-9.

92) Ketharanathan N, McCulloch M, Wilson C, Rossouw B, Salie S, Ahrens J, et al: Fluid overload in a South African pediatric intensive care unit. J Trop Pediatr 2014; 60: 428-33.

93) Li Y, Wang J, Bai Z, Chen J, Wang X, Pan J, et al: Early fluid overload is associated with acute kidney injury and PICU mortality in critically ill children. Eur J Pediatr 2016; 175: 39-48.

94) Abulebda K, Cvijanovich NZ, Thomas NJ, Allen GL, Anas N, Bigham MT, et al: Post-ICU admission fluid balance and pediatric septic shock outcomes: a risk-stratified analysis. Crit Care Med 2014; 42: 397-403.

95) Bhaskar P, Dhar AV, Thompson M, Quigley R, Modem V: Early fluid accumulation in children with shock and ICU mortality: a matched case-control study. Intensive Care Med 2015; 41: 1445-53.

96) Chen J, Li X, Bai Z, Fang F, Hua J, Li Y, et al: Association of fluid accumulation with clinical outcomes in critically ill children with severe sepsis. PLoS One 2016; 11: e0160093.

97) Flori HR, Church G, Liu KD, Gildengorin G, Mat- thay MA: Positive fluid balance is associated with higher mortality and prolonged mechanical ventilation in pediatric patients with acute lung injury. Crit Care Res Pract 2011; 2011: 854142.

98) Sinitsky L, Walls D, Nadel S, Inwald DP: Fluid overload at 48 hours is associated with respiratory morbidity but not mortality in a general PICU: retrospective cohort study. Pediatr Crit Care Med 2015; 16: 205-9.

99) Valentine SL, Sapru A, Higgerson RA, Spinella PC, Flori HR, Graham DA, et al: Fluid balance in critically ill children with acute lung injury. Crit Care Med 2012; 40: 2883-9.

100) Willson DF, Thomas NJ, Tamburro R, Truemper E, Truwit J, Conaway M, et al: The relationship of fluid administration to outcome in the pediatric calfactant in acute respiratory distress syndrome trial. Pediatr Crit Care Med 2013; 14: 666-72.

101) You JW, Lee SJ, Kim YE, Cho YJ, Jeong YY, Kim $\mathrm{HC}$, et al: Association between weight change and clinical outcomes in critically ill patients. J Crit Care 2013; 28: 923-7.

102) Schneider AG, Baldwin I, Freitag E, Glassford N, Bellomo R: Estimation of fluid status changes in critically ill patients: fluid balance chart or electronic bed weight? J Crit Care 2012; 27: 745.e7-12.

103) Han MJ, Park KH, Shin JH, Kim SH: Influence of daily fluid balance prior to continuous renal replacement therapy on outcomes in critically ill patients. J Korean Med Sci 2016; 31: 1337-44.

104) Glassford N, Eastwood G, Bellomo R: Physiological changes after fluid bolus therapy in sepsis: a systematic review of contemporary data. Crit Care 2014; 18: 696.

105) Bihari S, Teubner DJ, Prakash S, Beatty T, Morphett M, Bellomo R, et al: Fluid bolus therapy in emergency department patients: indications and physiological changes. Emerg Med Australas 2016; 28: $531-7$.

106) Bihari S, Prakash S, Bersten AD: Post resusicitation fluid boluses in severe sepsis or septic shock: 
prevalence and efficacy (price study). Shock 2013; 40: 28-34.

107) Aya HD, Rhodes A, Ster IC, Fletcher N, Grounds RM, Cecconi M: Hemodynamic effect of different doses of fluids for a fluid challenge: a quasirandomized controlled study. Crit Care Med 2016 Sep 20 [Epub]. http://dx.doi.org/10.1097/ CCM.0000000000002067.

108) Marik PE, Lemson J: Fluid responsiveness: an evolution of our understanding. Br J Anaesth 2014; 112: 617-20.

109) Monnet X, Pinsky MR: Predicting the determinants of volume responsiveness. Intensive Care Med 2015; 41: 354-6.

110) Malbrain ML, Marik PE, Witters I, Cordemans C, Kirkpatrick AW, Roberts DJ, et al: Fluid overload, de-resuscitation, and outcomes in critically ill or injured patients: a systematic review with suggestions for clinical practice. Anaesthesiol Intensive Ther 2014; 46: 361-80.

111) Finfer S, Bellomo R, Boyce N, French J, Myburgh $\mathrm{J}$, Norton R, et al: A comparison of albumin and saline for fluid resuscitation in the intensive care unit. N Engl J Med 2004; 350: 2247-56.
112) SAFE Study Investigators, Finfer S, McEvoy $S$, Bellomo R, McArthur C, Myburgh J, et al: Impact of albumin compared to saline on organ function and mortality of patients with severe sepsis. Intensive Care Med 2011; 37: 86-96.

113) Bannard-Smith J, Alexander P, Glassford N, Chan MJ, Lee M, Wong BT, et al: Haemodynamic and biochemical responses to fluid bolus therapy with human albumin solution, $4 \%$ versus $20 \%$, in critically ill adults. Crit Care Resusc 2015; 17: 122-8.

114) Waechter J, Kumar A, Lapinsky SE, Marshall J, Dodek P, Arabi Y, et al: Interaction between fluids and vasoactive agents on mortality in septic shock: a multicenter, observational study. Crit Care Med 2014; 42: 2158-68.

115) Beck V, Chateau D, Bryson GL, Pisipati A, Zanotti S, Parrillo JE, et al: Timing of vasopressor initiation and mortality in septic shock: a cohort study. Crit Care 2014; 18: R97.

116) Bai $X, Y u$ W, Ji W, Lin Z, Tan S, Duan K, et al: Early versus delayed administration of norepinephrine in patients with septic shock. Crit Care 2014; 18: 532 . 